\title{
Postdischarge Clinics: Hospitalist Attitudes and Experiences
}

\author{
Robert E. Burke, MD ${ }^{1,2 *}$, Patrick Ryan, MD²
}

${ }^{1}$ Hospital Medicine Section, Department of Veterans Affairs Medical Center, Eastern Colorado Health Care System, Denver, Colorado; ${ }^{2}$ Division of General Internal Medicine, Department of Medicine, University of Colorado School of Medicine, Denver Colorado.

Novel methods for improving transitions of care are needed. Hospitalist-run postdischarge clinics (PDCs) may improve access to postdischarge care, but require practice change from providers. We conducted a Web-based cross-sectional survey of hospitalists at 37 academic medical centers across the United States and a large private employer of hospitalists to assess the attitudes of hospitalists toward postdischarge care and PDCs. Two hundred twenty-eight of 814 hospitalists responded to the survey (28\%). Responding hospitalists commonly (55\%) experienced difficulty arranging outpatient follow-up, and felt that lack of access was responsible for most patient problems after discharge (61\%). Despite this, $62 \%$ felt hospitalists should not provide postdischarge care in a clinic, and $77 \%$ felt they would require extra compensation for work in a PDC. However, $74 \%$ thought such a clinic would decrease emergency department visits. Practicing in a PDC was associated with a trend toward positive attitudes about providing postdischarge care $(P=0.054)$. Responding hospitalists expressed difficulty arranging appropriate postdischarge care, confidence that PDCs would reduce postdischarge utilization, and reservations about working in a PDC, perhaps because of practical or financial concerns. These results are important given the current emphasis on reducing hospital readmissions. Further work evaluating the experience of hospitalists in PDCs is needed. Journal of Hospital Medicine 2013;8:578-581. (C) 2013 Society of Hospital Medicine
Transitions of care, which encompass the patient experience of hospital discharge to the community, are frequently associated with clinically and financially costly adverse events. ${ }^{1,2}$ One important element for reducing the risk of postdischarge adverse events is provision of timely follow-up by a clinician familiar with the patient and hospital course. ${ }^{3,4}$

However, achieving this ideal is becoming more difficult because of an increased demand for primary care services (due to expanding coverage of Medicare and Medicaid) and the decreased supply of primary care physicians. ${ }^{5,6}$ When a timely visit with a clinician is available postdischarge, the widening discontinuity between inpatient and outpatient care providers often means this clinician is lacking essential details of the hospitalization. ${ }^{7,8}$

One increasingly common innovation to improve postdischarge care access and continuity is to extend the role of inpatient providers (usually hospitalists) to provide care after discharge in a postdischarge clinic (PDC). ${ }^{9-11}$ These clinics require an expansion of a hospitalist's duties to the outpatient setting, a requirement that has met with hospitalist resistance in initial reports. ${ }^{12}$ However, little is known about

\footnotetext{
*Address for correspondence and reprint requests: Robert E. Burke, MD, Denver VA Medical Center, Mailstop 111, 1055 Clermont St., Denver, CO 80220; Telephone: 303-399-8020; Fax: 303-393-5199;

E-mail: Robert.Burke5@va.gov

Additional Supporting Information may be found in the online version of this article.

Received: July 15, 2013; Revised: August 11, 2013; Accepted: August 14,2013

2013 Society of Hospital Medicine DOI 10.1002/jhm.2085

Published online in Wiley Online Library (Wileyonlinelibrary.com).
}

hospitalists' experience with PDCs or attitudes toward postdischarge care. We aimed to explore these attitudes and experiences surrounding postdischarge care and PDCs.

\section{METHODS}

We conducted a cross-sectional 17-question Webbased survey of hospitalists at 20 academic and 17 VA medical centers across the United States. Hospital medicine faculty at each site were identified by their group leader; members of each group then received an email survey up to 3 times. To collect responses from nonacademic hospitalists, the survey was also distributed to a large national private hospitalist employer. Due to internal limitations at the employer site, sampling was not feasible, and thus a convenience sample was obtained. Hospitalists who were not clinically active or did not have computer access to complete the survey were excluded. Responses were initially gathered on a 4-point Likert scale; for comparisons between groups the scale was collapsed to a binary comparison using Fisher exact or $\chi^{2}$ tests. We included questions answered in partially completed surveys in both the numerator and denominator; questions not answered were excluded from both numerator and denominator. The denominator of all responses was noted. All analyses were conducted using SAS 9.3 (SAS Institute, Inc., Cary, NC). The study was approved by the Colorado Multiple Institutional Review Board.

\section{RESULTS}

Of 814 hospitalists, 228 responded to the survey $(28.3 \%)$. Table 1 illustrates characteristics of responding hospitalists, who were divided between university 


\section{TABLE 1. Study Participant Characteristics}

\begin{tabular}{lc}
\hline Characteristic & Respondents, No. (\%) \\
\hline Employing institution & \\
University hospital & $79(37.4)$ \\
Community, nonteaching & $62(29.4)$ \\
Community, teaching & $70(33.2)$ \\
Care environment & \\
Hospitalist providers & $98(46.4)$ \\
Housestaff providers & $94(44.6)$ \\
Primary care providers & $10(4.7)$ \\
Combination & $9(4.3)$ \\
Hospitalist group size (number of hospitalists) & \\
$1-5$ & $39(18.5)$ \\
6-10 & $50(23.7)$ \\
$11-20$ & $52(24.6)$ \\
$21-50$ & $59(28.0)$ \\
$>50$ & $9(4.3)$ \\
Hospital location-population & \\
Rural & $20(9.5)$ \\
Suburban & $47(22.3)$ \\
Urban & $144(68.2)$ \\
Hospital location-geographic & \\
West Coast & $11(5.2)$ \\
Midwest & $47(22.3)$ \\
Southern & $57(27.1)$ \\
East Coast & $21(10)$ \\
Southwest & $36(17.1)$ \\
Mountain & $32(15.2)$ \\
\hline
\end{tabular}

NOTE: Demographic characteristics of study participants are presented. Due to incomplete survey responses, the denominator is 211 for all responses presented.

TABLE 2. Attitudes Toward Postdischarge Care

\begin{tabular}{|c|c|c|}
\hline & $\begin{array}{l}\text { Agree, } \\
\text { No. (\%) }\end{array}$ & $\begin{array}{c}\text { Disagree, } \\
\text { No. (\%) }\end{array}$ \\
\hline Hospitalists should see patients in clinic after discharge & $87(38.2)$ & $141(61.8)$ \\
\hline Primary care responsible for problems after discharge & $198(86.8)$ & $30(13.2)$ \\
\hline Hospitalists responsible for patients after discharge & $113(49.6)$ & $115(50.4)$ \\
\hline Would welcome a PDC if employer required & $113(49.6)$ & $115(50.4)$ \\
\hline Would require extra compensation to work in a PDC & $175(76.8)$ & $53(23.2)$ \\
\hline Believe a PDC would reduce ED visits after discharge & $168(73.7)$ & $60(26.3)$ \\
\hline Would discharge patients earlier if could see after discharge & $116(50.9)$ & $112(49.1)$ \\
\hline Most postdischarge problems due to poor PCP access & $138(60.5)$ & $90(39.5)$ \\
\hline Easy to arrange timely follow-up with patient's PCP & $100(44.2)$ & $126(55.3)$ \\
\hline
\end{tabular}

NOTE: Abbreviations: ED, emergency department; PCP, primary care physician; PDC, postdischarge clinic. Attitudes toward postdischarge care are presented. All prompts received 228 responses. "Agree" encompasses responses of "strongly agree" and "agree"; the same is true for "disagree" (encompasses "strongly disagree" and "disagree"). Prompts are abbreviated due to space requirements; full text is available from the authors on request.

hospitals, community teaching hospitals, and community nonteaching hospitals in diverse practices in terms of location and group size.

Sixty-one percent of responding hospitalists believed most patient problems after discharge were due to poor follow-up with primary care providers, and $55 \%$ found it difficult to arrange timely primary care follow up (Table 2). Despite this, $87 \%$ thought patient problems after discharge should be cared for by primary care physicians, and $62 \%$ opposed the idea of hospitalists seeing patients in the clinic after discharge.
TABLE 3. Attitudes and Experiences Surrounding Postdischarge Clinics

\begin{tabular}{lc}
\hline & Respondents, No. (\%) \\
\hline Length of time inpatient providers responsible after discharge & \\
Responsibility ends at time of discharge & $65(28.5)$ \\
$1-3$ days & $40(17.5)$ \\
$4-7$ days & $57(25.0)$ \\
2 weeks & $41(18.0)$ \\
4 weeks & $20(8.8)$ \\
3 months & $3(1.3)$ \\
$\geq 3$ months & $2(0.9)$ \\
Postdischarge clinic present & $20(8.8)$ \\
Considered starting a postdischarge clinic* & $62(30.5)$ \\
Starting in next year & \\
Are satisfied with experience in postdischarge clinic & ${ }^{\ddagger}$ \\
Think patients are satisfied/highly satisfied & $6(3.3)$ \\
& $17(85)$ \\
\hline
\end{tabular}

NOTE: Attitudes and experiences with postdischarge care are presented. Unless noted, 228 responses were received.

*Out of 203 responses.

†Out of 182 responses.

${ }^{\ddagger}$ Out of 20 responses.

When asked if hospitalists were responsible for patients after discharge from the hospital, only 50\% responded positively. However, when asked how long hospitalists were responsible for patients after discharge, $71 \%$ gave a response longer than hospital discharge, including $60 \%$ who believed this responsibility ended at 1 week or less following discharge. A minority $(12 \%)$ felt it extended to 1 month following discharge (Table 3).

Responding hospitalists expressed confidence in a PDC to reduce postdischarge emergency department visits $(74 \%)$. However, most felt they would require extra compensation to staff a PDC (77\%). They were divided on whether they would discharge patients from the hospital earlier if they could see those patients in postdischarge follow-up $(51 \%$ would discharge patients earlier).

Compared to those who had not experienced a PDC, responding hospitalists who had provided care in a PDC trended toward responding more positively that hospitalists should provide postdischarge care $(P=0.054)$. Few responding hospitalists had such exposure $(8.8 \%)$ at the time of the survey. Although $31 \%$ had considering starting a PDC, only $3 \%$ were starting in the next year. Of responding hospitalists with exposure to a PDC, $70 \%$ were satisfied with the experience and $85 \%$ felt their patients were satisfied. Responses did not vary by type of practice (academic vs nonacademic), group size, geographic location, or by exposure to a PDC except as above.

\section{DISCUSSION}

Responding hospitalists reported encountering significant difficulty arranging appropriate postdischarge appointments with primary care providers and feel this contributes to postdischarge complications. Nearly 
$75 \%$ of those surveyed felt a hospitalist-run PDC would be effective in reducing postdischarge emergency department visits, presumably in part due to improved access to postdischarge care. However, $62 \%$ of responding hospitalists opposed providing this type of care, though those who had experienced a PDC were somewhat more likely to view providing care in a PDC favorably. Survey responses largely reflect attitudes rather than experience with PDCs, because very few respondents had ever worked in a PDC.

The juxtaposition of the confidence expressed in PDCs to reduce postdischarge emergency department visits with the less enthusiastic views of respondents about providing care in a PDC was surprising. Several explanations are possible. First, providing such care is outside the usual scope of practice of most hospitalists, and preliminary reports indicate hospitalists, as self-selected inpatient providers, may not initially welcome this opportunity. ${ }^{12}$ Second, responding hospitalists identified the need for extra compensation for providing this care, suggesting they would see staffing a PDC as a burden requiring extra payment. Third, only $12 \%$ of respondents felt their responsibility to their discharged patients extended to 1 month following discharge. Given this, hospitalists may not feel enough personal ownership over 30-day readmission rates to justify the additional clinical demand of staffing a PDC. ${ }^{13}$

In fact, $29 \%$ of responding hospitalists felt their responsibility to the patient ended at the time of discharge. Respondents may have interpreted "responsibility" differently, and we cannot rule out response bias given our lower-than-expected response rate. However, we had anticipated many fewer hospitalists would respond this way given professional hospitalist societies have endorsed guidelines for improved transitions of care, which clearly delineate the key role hospitalists play in care transitions. ${ }^{14}$

Although fewer than $10 \%$ of respondents had worked in a PDC, nearly one-third reported considering starting such a practice in the future, underscoring the importance of understanding hospitalist attitudes and experiences when creating a PDC and the significant barriers to arranging appropriate postdischarge care identified by survey respondents. The barriers to establishing a PDC may explain why few planned to start a PDC in the next year.

This study should be interpreted in the context of its design. Due to limitations in survey delivery, more rigorous sampling designs could not be used, and efforts were instead made to deliver the survey to a diverse group of hospitalists. The survey response rate was lower than anticipated and this increases the risk of response bias. Though this response rate is characteristic of other surveys of hospitalists, responses may have been from a selected population and therefore not representative of all hospitalists. ${ }^{15}$ We sampled from a variety of practice venues, locations, academic and community practices, and practice group sizes to try to minimize this bias. Due to the low exposure rate to PDCs, hospitalist responses to experiences with PDCs should be considered exploratory.

We asked about similar content areas in the survey in multiple questions to maximize content validity; this resulted in variations in the degree of agreement or disagreement to similar prompts. For example, $62 \%$ of hospitalists opposed seeing patients in the clinic after discharge when directly asked, but nearly $50 \%$ said they would welcome the opportunity to work in a PDC if their employer required it. In another example, $50 \%$ of respondents said their responsibility for the patient ended at time of discharge, but when asked about duration of responsibility, $30 \%$ identified time of discharge as the limit. When reporting and interpreting results, we have tried to highlight responses to questions that ask most clearly and directly about the content of interest (rather than general themes), but this interpretation may also be subject to bias.

The time after hospital discharge is one of heightened risk for adverse events for the recently discharged patient. Hospitalist-run postdischarge clinics may offer improved postdischarge care access and continuity; more research is needed on the effects of such clinics on patient outcomes, including postdischarge utilization. Until then, physicians and hospitals considering establishing PDCs should consider the barriers responding hospitalists identified to working in such a clinic, as well as the confidence they expressed in PDCs to reduce subsequent utilization.

Disclosures: Dr. Burke had full access to all of the data in the study and takes responsibility for the integrity of the data and the accuracy of the data analysis. The views expressed in this article are those of the authors and do not necessarily represent the views of the Department of Veterans Affairs. Dr. Burke was supported by grant funding from the Colorado Research Enhancement Award Program to Improve Care Coordination for Veterans. Dr. Ryan has no conflicts of interest to disclose.

\section{References}

1. Forster AJ, Murff HJ, Peterson JF, Gandhi TK, Bates DW. The incidence and severity of adverse events affecting patients after discharge from the hospital. Ann Intern Med. 2003;138(3):161-167.

2. Jencks SF, Williams MV, Coleman EA. Rehospitalizations among patients in the Medicare fee-for-service program. N Engl J Med. 2009; 360(14):1418-1428.

3. Hernandez AF, Greiner MA, Fonarow GC, et al. Relationship between early physician follow-up and 30-day readmission among Medicare beneficiaries hospitalized for heart failure. JAMA. 2010; 303(17):1716-1722.

4. Misky GJ, Wald HL, Coleman EA. Post-hospitalization transitions: Examining the effects of timing of primary care provider follow-up. $J$ Hosp Med. 2010;5(7):392-397.

5. Colwill JM, Cultice JM, Kruse RL. Will generalist physician supply meet demands of an increasing and aging population? Health Aff (Millwood). 2008;27(3):w232-w241.

6. Association of American Medical Colleges. June 2010.The impact of health care reform on the future supply and demand for physicians updated projections through 2025. Available at: http://www.aamc. org/download/158076/data/updated_projections_through_2025.pdf. Accessed May 1, 2012.

7. Sharma G, Fletcher KE, Zhang D, Kuo YF, Freeman JL, Goodwin JS. Continuity of outpatient and inpatient care by primary care physicians for hospitalized older adults. JAMA. 2009;301(16):1671-1680. 
8. Fletcher KE, Sharma G, Zhang D, Kuo YF, Goodwin JS. Trends in inpatient continuity of care for a cohort of Medicare patients 19962006. J Hosp Med. 2011;6(8):438-444.

9. Beresford L. Is a post-discharge clinic in your hospital's future? The Hospitalist. December 2011 Available at: http://www.the-hospitalist.org/details/article/1409011/Is a Post_Discharge_Clinic in_Your Hospitals_future.html. Accessed May 1, 2013.

10. van Walraven C, Mamdani M, Fang J, Austin PC. Continuity of care and patient outcomes after hospital discharge. J Gen Intern Med. 2004;19(6):624-631.

11. Diem SJ, Prochazka AV, Meyer TJ, Fryer GE. Effects of a postdischarge clinic on housestaff satisfaction and utilization of hospital services. J Gen Intern Med. 1996;11(3):179-181.
12. Doctoroff L. Interval examination: establishment of a hospitaliststaffed discharge clinic. J Gen Intern Med. 2012;27(10):1377-1382.

13. Patient Protection and Affordable Care Act (PPACA).Public Law 111-148 2010. Available at: http://www.gpo.gov/fdsys/pkg/PLAW111publ148/pdf/PLAW-111publ148.pdf. Accessed January 10, 2013.

14. Snow V, Beck D, Budnitz T, et al. Transitions of Care Consensus policy statement: American College of Physicians, Society of General Internal Medicine, Society of Hospital Medicine, American Geriatrics Society, American College of Emergency Physicians, and Society for Academic Emergency Medicine. J Hosp Med. 2009:4(6):364-370.

15. Hinami K, Whelan CT, Miller JA, Wolosin RJ, Wetterneck TB. Person-job fit: an exploratory cross-sectional analysis of hospitalists. $J$ Hosp Med. 2013;8(2):96-101. 